\title{
Research on Project Teaching Method of Logistics Teaching*
}

\author{
Fanlei Meng \\ Feixian School, Linyi University, Feixian, Shandong, 273400, P.R. China \\ lydxmfl@126.com
}

\begin{abstract}
This paper applies project teaching method to logistics teaching course and explores its application in practical teaching process. It also illustrates the existing problems, the choosing of projects, implement and requirements in detail.

Index Terms - Project teaching method, logistics, teaching study

\section{Introduction}

In 1990s, due to the introduction of foreign logistics concepts and the rapid development of information technology, the domestic modern logistics begins to take shape. It is a top priority to cultivate professionals in domestic logistics industry. Then how to do it? It is a necessity to break the conventional teaching models. Coincidently, the project teaching accords to the requirement of new teaching methods. It is the best way for shortening the gap between theory and practice to introduce project teaching methods to logistics teaching. Therefore, it is of crucial importance to study and popularize the project teaching methods in logistics.
\end{abstract}

\section{Project Teaching Method}

Project teaching method is a practice-oriented teaching activity in which the students finish a complete project with the guide of the teacher. The project refers to a specific and practical assignment which is carried out by the students together with the teacher. This method is intended to promote teaching in the form of project.[1]. And under the leadership of the teacher, the students, which are divided into different teams, solve the problems creatively and complete the projects through doing the work of information collection, selection, arrangement, research and analysis. During this process, the students participate in the study actively and, in the meantime, they can build up their knowledge system. Logistics is quite a practical major studying the logistic operation of the business enterprises. It's significant to bring in project teaching method in logistics teaching, which is helpful for improving the students' capability of researching, practicing and social interaction.

\section{The Main Characteristics of the Logistics Project Teaching Method}

\subsection{The comprehensiveness of teaching goal.}

Through information collection, project decision-making, project implementation, achievement exhibition, evaluation and so on, a series of activities can develop various abilities of students. Such as observational ability, practical ability, capacity for research and analysis, disposing capacity, application ability and social competence, etc.

\subsection{The systematicness of teaching activity.}

Project teaching emphasizes that teaching activities should meet or exceed students' expectations, for the purpose, each teaching course should be precisely defined and could eventually provide deliverable outcomes; emphasize that teaching is the unity of students learning process and teaching management process; emphasize that teaching method is the consolidation and integration of modern teaching tools and methods; emphasis on teaching and environmental relevance. In teaching, the learning process becomes a participatory and creative practice, which does not focus on the end result, but the process of project. Therefore, in the teaching process, it should take the form of scene teaching to be more.[2].

\section{Project Teaching Employment in Logistics Management}

The Project Pedagogics insists that students have their own ways of researching, generalizing and solving the problems. Therefore, this method can be much more adaptive to the requirements of quality-oriented education, compared to the traditional teaching methods.

\subsection{The instrument before implement should be concise and clear}

Teachers should give proper instrument to students which includes explain the brand new knowledge and the specific implement of projects before they are going to finish the projects individually. The explanation of new knowledge should be focused on the important points to avoid repeating. In traditional teaching methods, it is a key part to teach new knowledge. Usually, after finishing the explanation of new knowledge, teachers will repeat some confusable points and teach students their own practical experiences. However, in project teaching method, the essence of it is to help students discover knowledge, solve problems and uplift skills during finishing tasks individually. Therefore, the confusing knowledge should be discovered by students themselves but not given by teachers directly, so is the practical experiences. It can be concluded that project teaching method should put focus on the key content, refining the teaching course with

\footnotetext{
* This work was supported by the Projects for Reformation of Chinese Universities Logistics Teaching and Research (JZW2013064, JZW2013065).
} 
practical operating according to some easy cases.[3] Doing so, it is helpful for students to absorb knowledge and have a good start for the project implement.

\subsection{Conducting project teaching requires full and specific preparation before class.}

Conducting project teaching requires full and specific preparation before class. That is to say, compared with traditional teaching, project teaching is more demanding for both teachers and students. Viewed from the teachers, a delicately designed teaching plan is necessary to make the 45minute class more efficient. Furthermore, how to construct the project activity decides whether it can arouse students' interest, motivate them to turn to their gained knowledge, to collect related materials, to study autonomously, and inspire their confidence. In addition, familiar with the content of project and having a deep research upon it as well as the preparation of knowledge to which project discussion may be concerned are also needed. Apart from that, project teaching should be in association with other teaching methods, and the lecture should be delivered gracefully. During the process of project teaching, students have to collect three times the amount of information and material which are requested in traditional teaching. As a result of that, teachers have to equip students with the ability to collect diverse information, making full use of contemporary teaching methods to provide students with sorts of study resource, too. Teachers have to make clear of what role they play in teaching at the same time.

In a word, the feature of project teaching is that teachers conduct teaching activity according to students' advantages. If the activity can be used to teach students about their emotion, attitude and value, that will be even better.

\subsection{The step-by-step principle in teaching}

We must follow the step- by- step principle while teaching, and gradually improve it. One of the factors in the success of the project teaching method is to arouse the students' interest on studying. In order to solve this problem, we must focus on the step- by- step teaching principle and complete the teaching project in accordance with the teaching contents and the students' progress, helping them learn to how to discover problems, analyze problems, and find out methods to solve it. With repeated training, the students' ability can be improved, then teachers can let students finish the project all by themselves. The initiative of students' independent learning cannot be ignored in case of going against the original significance of the project teaching. Project selection is the key to learning. Meanwhile, material selection for the project is also important, it must be based on the teaching contents and the practical object, and it should not only contain the elementary teaching knowledge, but also can arouse the enthusiasm of the students to tackle problems. The knowledge and shill contents involved should be familiar with the student and conform to the lately development theory thus can help to improve the student's capability.

\subsection{The teaching forms must be flexible and diversified}

There are many teaching styles which can be chosen in project teaching method. Which one can be chosen to teach must be based on the teaching goals and students' former experiences and learning tasks. It will affect the teaching effect if one teaching style is consistently used. For instance, the way to cultivate students' social ability is to ask them to communicate with each other more frequently, thus helping them learn how to contact with other people, how to cooperate with others and how to solve the conflicts with others. In all, it can help stimulate the interest and improve the operating skills of students to use practical imitation. Besides, it is based on the specific features of project to decide whether finishing it by individual or by groups. A conclusion is drawn through multiple practices of teaching: it's appropriate for students to finish the items which purely aim at studying the brand new knowledge individually, while it's more suitable for them to work in groups when it comes to the complicated projects. It is because that each student has his own special ability, so the complementary in knowledge can help them solve more problems. Indeed, finishing projects individually and by groups are both advantageous in cultivating students' ability. Therefore, the implement of projects should take students' development into consideration so as to establish working groups more flexibly and improve students' ability in more fields.

\section{Problems in Project Teaching Method.}

\subsection{Problem in textbooks.}

At present, the textbooks and experiment introduction books that are suitable for project teaching in logistics courses are lacking. In most textbooks, the cases are not that typical and representative and the theories are lacking in those books. It is suggested that the cases for project teaching be further improved based on the conclusion of practical experiences to write the appropriate textbooks and experimental introduction books, thus meeting the need of new teaching mode[4].

\subsection{Problem in the combination of theory and practice}

Project teaching is a method of teaching and practicing. What teachers should do is not to instill theories to students but combine theories and practice so as to help students study further step by step, thus understand knowledge in practices and apply it to problem solving. [5] However, it is of equal importance to master theories, so it is suggested the focus be put on theories teaching in the former ten minutes of a lesson and then apply these theories to practical project.

\subsection{Problem in the relationship between teachers and students}

Project teaching attach much importance to students' activeness in study, while it does't mean what teachers should do is only to guide them study actively. In project teaching, teachers should both be capable of specialized knowledge teaching and practical operating and management. [6].In this way, teachers can lead students implement projects in all aspects during guiding them study actively and stimulate their 
enthusiasm in participating the projects.

\subsection{Problem in grouping students}

To great extent, it cannot be ignored for the matter of grouping students, because it exerts big influence in teaching effect. In project teaching, students are all divided into groups to co-finish projects. Theoretically speaking, every group is responsible for a project. Because the problems they may encounter during the finishing process are closely related to their mastering of theory knowledge [7], so students should be grouped with different individuals to reach a complementary effect. This is also helpful for students to learn from each other.

\section{Conclusions}

\subsection{The choosing of projects}

During project teaching in logistics major of colleges, the choosing of projects should be given to top priority, because it directly decide the teaching effect and students' interest in it. Therefore, appropriate project should be chosen in project teaching in logistics major. Then what is appropriate project? First, the project is equipped with explicit purpose. It must accord with the developing goal in this major and the requirement of students' future job seeking. Second, the difficulty value and teaching time of the projects should accord with students' knowledge and capacity. Based on the knowledge mastered by college students and the working content in future job, the projects should not be too difficult. Based on the students' study time, the project should not last for too long, one and a half month is appropriate for a project.

\subsection{The implement of organizing projects}

During implementing the projects, the background and purpose of the projects should be firstly explained to students. Secondly, students should be divided into groups according to the project requirement and appoint a leader of every group. Students can distribute tasks by themselves and implement projects.

\subsection{The requirement of project achievement}

The results of projects should be the document and plans which are instructive to the practical work.

\section{Acknowledgment}

This work was supported by the Projects for Reformation of Chinese Universities Logistics Teaching and Research (JZW2013064, JZW2013065). The author wish to give their sincere thanks to the editor and the anonymous referees for their valuable suggestions, and helpful comments which improved the presentation of the paper.

\section{References}

[1] G.J. Liu, modern project management Tutorial, People's University of China Press, Beijing, china, 2009. (In Chinese).

[2] F.Dai, J. F. Li, project-based mode of teaching and student ability in practice of cultivating, Nanchang High-designed journal, Nanchang, china, 2003. (In Chinese).

[3] L.Guo, The application of project teaching method in logistics talents training. Education and profession, 2007. (In Chinese)

[4] Sh.y.Xiao, Study on project teaching method in computer teaching course. Study on electrical education, 2003. (In Chinese)

[5] Gangqiao Liu, Ming Li \& Jianhua Shi (2010).The construction of the practical teaching systems of logistics based on engineering in higher vocational school. Journal of Shun De Vocational Technical Institute, (1):37-40.

[6] Ding Li (2007).Explorations of practical teaching patterns in logistics curriculum. Study of Teaching, (4):363-364.

[7] D. Zhu, The thinking of innovative of logistics management major and applied undergraduate talents cultivation. Journal of logistics. 